\title{
Wpływ stereometrii powierzchni na właściwości adhezyjne warstwy naniesionej metodą LPCS
}

\section{The surface stereometry influence on the adhesive properties of LPCS made layer}

\section{Streszczenie}

Metoda niskociśnieniowego natryskiwania na zimno (low pressure cold spray - LPCS) jest wykorzystywana do wykonywania różnego rodzaju warstw przewodzących, antykorozyjnych, izolujących itp., jak również uzupełniania ubytków materiału. Proces może być zautomatyzowany, poprzez podłączenie palnika urządzenia do robota bądź manipulatora, lub też obsługiwany ręcznie, co czyni go bardzo mobilnym. Jednakże automatyzacja jest o tyle korzystna, że umożliwia uzyskanie równomiernie nałożonej warstwy o pożądanej grubości. Ze względu na dużą liczbę współzależnych parametrów, w jednym przejściu palnika można uzyskać ścieg o grubości rzędu od kilkuset mikrometrów do nawet kilku milimetrów. Powstaje wskutek tego warstwa o zróżnicowanej falistości i chropowatości powierzchni. W przedstawionym artykule skupiono się na wyznaczeniu wpływu parametrów procesu LPCS, dających warstwę o określonej falistości oraz chropowatości, przy grubości warstwy do $1 \mathrm{~mm}$. W badaniach wykorzystano proszek aluminium z domieszką korundu, co pozwoliło uzyskać warstwy kompozytowe, które znajdują szerokie zastosowanie jako zabezpieczenie stali przed korozją.

\section{Abstract}

Low Pressure Cold Spray (LPCS) is used to perform various kinds of conductive layers, anti-corrosion, insulating, etc., as well as filling the discontinuities in the material surface. The process can be automated by connecting the burner unit to the robot or manipulator and manual, making it extremely mobile. However, the automated system is advantageous in that it allows a uniformly applied layers of a desired thickness. Due to the large number of interdependent parameters in a single burner pass can be seam thickness of the order of several hundred microns to several millimeters - this results in a layer of varying waviness and roughness of the surface. The article focuses on determining the impact of LPCS process parameters on layer having a particular waviness and roughness, and the layer thickness of $1 \mathrm{~mm}$. In the test were used aluminum powder mixed with alumina, allowing for composite layers, which is widely used to protect steel from corrosion.

\section{Wstęp}

Metoda gazodynamicznego natryskiwania na zimno (cold spraying) została wynaleziona w latach 80. XX w. w Rosji i od tamtej pory, ze względu na liczne zalety, podlega nieustannemu rozwojowi. Prace dotyczą

Mgr inż. Marcin Winnicki, mgr. inż. Aleksandra Małachowska, mgr inż. Paweł Sokołowski - Politechnika Wrocławska. przede wszystkim optymalizacji stanowiska w wyniku analizy termodynamiczne różnorakich dysz i podajników proszku, umożliwiających zwiększenie wydajno-

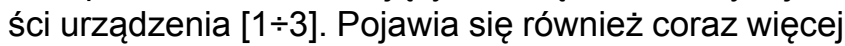
badań dotyczących samych warstw, ich mikrostruktury oraz właściwości mechanicznych $[4 \div 6]$. Wciąż jednak brak jest dokładnych danych na temat adhezji czy też stereometrii warstw. Dotyczy to zwłaszcza odmiany niskociśnieniowej gazodynamicznego natryskiwania na zimno (LPCS), mającej duże możliwości zastosowania w przemyśle, ze względu na dobre właściwości warstw i stosunkowo, w porównaniu do metody 
wysokociśnieniowej, niewielkie nakłady finansowe. W tym kontekście istotna staje się optymalizacja właściwości warstwy i powiązanie ich z parametrami procesu.

W procesie LPCS głównymi parametrami mającymi wpływ na otrzymaną grubość warstwy są masowe natężenie przepływu proszku, prędkość liniowa palnika, temperatura oraz ciśnienie gazu roboczego, rodzaj zastosowanego gazu roboczego (hel, azot, powietrze), granulacja proszku oraz odległość końca dyszy od podłoża [7, 8]. Dobór parametrów umożliwia uzyskanie szerokiego zakresu grubości warstwy w jednym przejściu. Jak się okazało na podstawie badań, znaczny wpływ na grubość budowanej warstwy ma również materiał podłoża [7]. Przy zastosowaniu stopów aluminium, niklu oraz mosiądzu jako materiału podłoża, największą grubość warstwy otrzymano przy stopie Al 6061, natomiast najmniejszą dla stopu niklu Haynes 556. Autorzy tłumaczą to niską wartoścą współczynnika ściskania cząsteczek proszku przy miękkim podłożu, jakim jest aluminium.

Zastosowane w procesie parametry mają bezpośredni wpływ na przyrost grubości warstwy, co z kolei przekłada się na jej falistość i chropowatość. Goyal i inni [7] skupili się na optymalizacji grubości nałożonej metodą cold spray warstwy miedzi na podłożach stopu aluminium Al 6160, mosiądzu oraz stopu niklu Haynes 556, przy zastosowaniu różnych parametrów. Zauważyli, że grubość powłoki wzrasta w miarę wzrostu ciśnienia i prędkości natryskiwanego proszku [8]. Prędkość proszku, a co za tym idzie - także jego odkształcenie podzas kontaku z podłożem - ma również kluczowy wpływ na chropowatość i falistość powłok [9, 10]. W pracy [9] zauważono spadek chropowatości powłok tytanowych na podłożu aluminiowym wraz ze wzrostem prędkości nanoszonego proszku spowodowanej zwiększeniem temperatury gazu. Większa prędkość powoduje większe odkształcenie cząstki podczas uderzenia i tym samym również większą gęstość, stąd powłoki uzyskane podczas natryskiwania przy wyższych temperaturach charakteryzowały się mniejszą chropowatością oraz większą mikrotwardością oraz modułem Younga [9].

Aluminium jest materiałem często wykorzystywanym w metodzie natryskiwania na zimno ze względu na małą masę oraz dużą ciągliwość. Naniesione tą metodą warstwy cechują się dużą odpornością na korozję, zbliżoną do czystego aluminium, oraz twardością wyższą od blachy aluminiowej walcowanej na zimno [11]. Wynika to z mechanizmu połączenia ziaren proszku. Kluczową rolę przy zwiększaniu odporności na korozję warstwy stanowi zmniejszenie jej porowatości. Obniżenie porowatości związane jest ze wzrostem gęstości warstwy, co można osiągnąć przez dodatek fazy ceramicznej.

Wprowadzenie do proszku metalu fazy ceramicznej wiąże się z wieloma korzyściami $[12,13]$. Jak wykazano

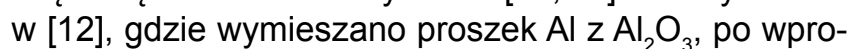
wadzeniu ceramiki wydajność procesu natryskiwania zwiększała się od 30\% do ok. 50\%. Dodatkowo, w wyniku ubijania ciągliwego metalu twardą fazą możliwy jest znaczny spadek porowatości z 30\% dla czystego aluminium do nawet $1 \%[12,13]$, jak również zwiększenie

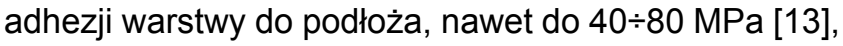
twardości oraz odporności na ścieranie [14].

\section{Metodyka badań}

Warstwy natryskiwano za pomocą urządzenia do niskociśnieniowego natryskiwania na zimno DYMET 413. Urządzenie to wyposażone jest w palnik z wewnętrznie osadzoną nagrzewnicą oraz dwa podajniki proszku. Palnik przymocowany jest do ramienia manipulatora, który sterowany jest pomocą komputera i pracuje w 3 osiach.

Do badań wykorzystano sferyczny, komercyjny proszek Al o granulacji < $50 \mu \mathrm{m}$ z domieszką korundu $\mathrm{Al}_{2} \mathrm{O}_{3}$ w proporcji 40/60\% wag. (rys. 1). Materiał podłoża stanowiła płytka ze stali S235JR o wymiarach 50x100 mm, grubości 3 mm oraz składzie chemicznym: $0,2 \%$ C (max), 1,4\% Mn (max), 0,045\% P, 0,045\% S, $0,009 \%$ N. Powierzchnia podłoża przed natryskiwaniem została poddana obróbce strumieniowo-ściernej z użyciem korundu o granulacji ziaren poniżej $350 \mu \mathrm{m}$ podanego pod ciśnieniem 0,6 MPa, dzięki czemu uzyskała chropowatość wynoszącą Ra $=5,0 \mu \mathrm{m}$. Jako gaz roboczy w procesie natryskiwania wykorzystano powietrze.

W przeprowadzonych badaniach zastosowano okrągłą dyszę de Lavala, stałą odległość od podłoża wynoszącą I = $20 \mathrm{~mm}$ oraz jedno przejście palnika wzdłuż osi $X$ (rys. 2). Szerokość jednego ściegu dla dyszy o średnicy $\mathrm{d}=5 \mathrm{~mm}$, przy natryskiwaniu w odległości I $=20 \mathrm{~mm}$, wynosi średnio $b=7,4 \mathrm{~mm}$. Topografia ściegu oraz jego chropowatość uzależnione są ściśle od parametrów procesu, tj. masowego natężenia przepływu proszku $\mathrm{m}_{\mathrm{p}}$, prędkości liniowej palnika $\mathrm{v}_{\mathrm{l}}$, temperatury $\mathrm{T}_{\mathrm{g}}$ oraz ciśnienia $p_{g}$ gazu roboczego, rodzaju zastosowanego gazu roboczego (hel, azot, powietrze), granulacji proszku $D_{p}$ oraz odległości końca dyszy od podłoża I.

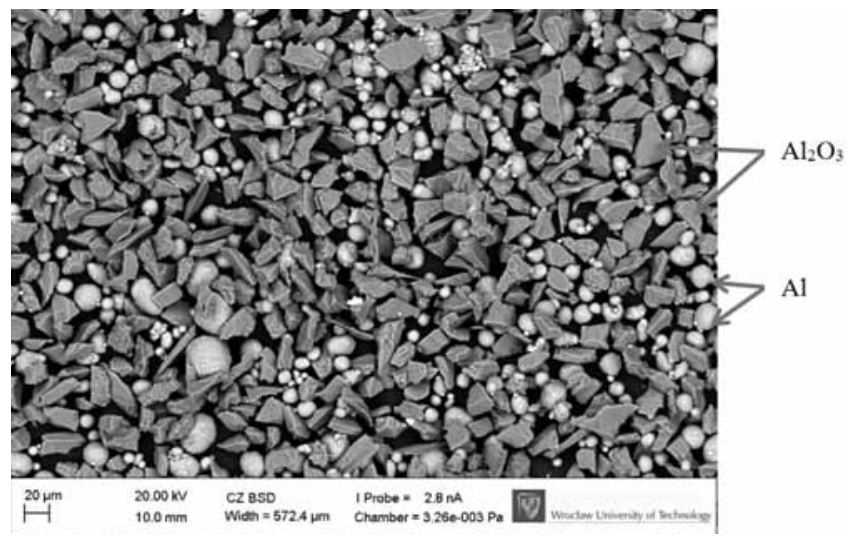

Rys. 1. Zastosowany w badaniach proszek sferyczny $\mathrm{Al} z$ domieszką $\mathrm{Al}_{2} \mathrm{O}_{3}$ (proporcja 40\% Al / 60\% $\mathrm{Al}_{2} \mathrm{O}_{3}$ ), granulacja $<50 \mu \mathrm{m}$

Fig. 1. Spheroidal $\mathrm{Al}$ powder with $\mathrm{Al}_{2} \mathrm{O}_{3}$ addition $\left(40 \% \mathrm{Al} / 60 \% \mathrm{Al}_{2} \mathrm{O}_{3}\right)$, granulation $<50 \mu \mathrm{m}$ 


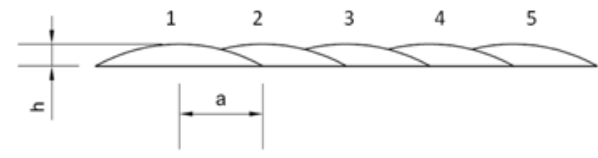

b)

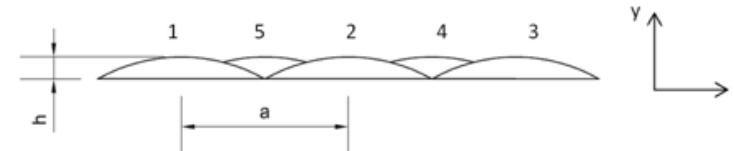

Rys. 2. Wzór topografii warstwy uzyskanej w jednostopniowym (a) i dwustopniowym przejściu palnika (b)

Fig. 2. Surface topography scheme after single pass (a) and double pass (b) of burner

Parametry wejściowe do procesu stanowiły dane uzyskane w poprzednich badaniach, gdzie wykorzystano planowanie eksperymentu metodą Taguchiego do określenia wpływu parametrów na grubość, falistość i chropowatość powierzchni. Umożliwiło to uzyskanie jednego ściegu warstwy o pożądanej grubości w jednym przejściu palnika. Stąd przeprowadzone badania dotyczyły analizy wybranych grubości w skali warstwy kilkuściegowej i przypisanych im parametrów procesu (tabl. I). Szerokość warstw naniesionych w prowadzonych badaniach wynosiła $40 \mathrm{~mm}$, a długość obejmowała 5 przejść palnika w osi $X$ i była uzależniona od odległości między kolejnymi przejściami palnika a (rys. 2). Ostatecznie wyznaczono grubość $H$, chropowatość $\mathrm{Ra}$, falistość wzdłużną powierzchni $\mathrm{Wa}_{1}$ oraz falistość poprzeczną powierzchni $\mathrm{Wa}_{2}$ warstwy (wg PN-EN ISO 4287:1999).

Przykładowe topografie warstwy podano schematycznie na rysunku 2. Jeżeli palnik nachodził na poprzedni ścieg, otrzymano warstwę o przejściu jednostopniowym (rys. 2a), dla której parametr a wynosił $3,7 \mathrm{~mm}$. Jeśli zaś ściegi nie nachodziły na siebie, palnik wracał i wypełniał powstałe rowki w przejściu dwustopniowym (rys. 2b). W tym przypadku wartość parametru a wynosiła $7,4 \mathrm{~mm}$.

Pomiar grubości, falistości oraz chropowatości warstw naniesionych metodą LCPS przeprowadzono przy wykorzystaniu profilografometru stacjonarnego Form Talysurf 120L, o końcówce pomiarowej zakończonej stożkiem diamentowym z kątem wierzchołkowym $60^{\circ}$ i promieniem zaokrąglenia $r=2 \mu \mathrm{m}$.

Tablica I. Parametry procesu nanoszenia odpowiednich grubości warstw przy badaniu właściwości stereometrycznych

Table. I. Process parameters for desired thickness layer deposition in the stereomtric properties testing

\begin{tabular}{|c|c|c|c|c|}
\hline \multirow{2}{*}{$\begin{array}{c}\text { Grubość } \\
\text { ściegu h } \\
\mu \mathrm{m}\end{array}$} & $\begin{array}{c}\text { Masowe natę- } \\
\begin{array}{c}\text { żenie poda- } \\
\text { wania proszku } \\
\mathrm{m}_{\mathrm{p}}, \mathrm{g} / \mathrm{s}\end{array}\end{array}$ & $\begin{array}{c}\text { Prędkość } \\
\text { liniowa } \\
\mathrm{v}_{\mathrm{l}}, \mathrm{mm} / \mathrm{min}\end{array}$ & $\begin{array}{c}\text { Ciśnienie } \\
\text { gazu } \\
\mathrm{p}_{\mathrm{g}}, \mathrm{MPa}\end{array}$ & $\begin{array}{c}\text { Temperatura } \\
\text { gazu T }_{\mathrm{g}},{ }^{\circ} \mathrm{C}\end{array}$ \\
\hline 250 & 0,34 & 1200 & 0,8 & 500 \\
\hline 500 & 0,76 & 600 & 0,5 & 500 \\
\hline 750 & 1,73 & 1200 & 0,7 & 500 \\
\hline 1000 & 0,76 & 300 & 0,6 & 400 \\
\hline
\end{tabular}

Chropowatość oraz falistość wzdłużną powierzchni określono parametrami $\mathrm{Ra}$ oraz $\mathrm{Wa}_{1}$, dokonując pomiaru po powierzchni wzdłuż ściegu na odcinku $30 \mathrm{~mm}$. Grubość ściegu h, grubość warstwy H oraz falistość poprzeczną $\mathrm{Wa}_{2}$ wyznaczono przez 1 pomiar wykonany w poprzek próbki, w odległości $20 \mathrm{~mm}$ od krawędzi bocznej. W celu zobrazowania zmiany profilu warstwy dla jednego $z$ przypadków opisanego w dyskusji wykonano 3 pomiary falistości poprzecznej $\mathrm{Wa}_{2}$.

\section{Wyniki i dyskusja}

Przeprowadzone doświadczenia wykazały, że grubość warstw przy natryskiwaniu w 5 przejściach palnika jest znacznie większa od grubości pojedynczego ściegu. Związane jest to $z$ nagrzewaniem się dyszy oraz podłoża w wyniku oddziaływania temperatury przepływającego gazu. Zmianę grubości warstwy, na przykładzie próby 7 , przedstawiono na rysunku 3 . Celowo w tym przypadku przeprowadzono 3 pomiary profilu w odległości: $5 \mathrm{~mm}, 20 \mathrm{~mm}$ i $35 \mathrm{~mm}$ od krawędzi bocznej (rys. 4). Największą zmianę uwidacznia ścieg $\mathrm{nr} 1$. Wraz z nagrzaniem dyszy zmieniają się warunki panujące w jej wnętrzu, zmniejszają się straty ciepła i jednocześnie wzrasta prędkość ziaren proszku w strumieniu. Podgrzanie podłoża, jak udowodniono w pracach $[15,16]$, powoduje wzrost wydajności procesu, co jest równoznaczne z osadzeniem większej ilości proszku i uzyskaniem grubszej warstwy. Zaobserwowano, że proces stabilizuje się dopiero po 3 przejściu palnika, uzyskując regularną, powtarzającą się wydajność. Wyniki pomiaru grubości warstwy $\mathrm{H}$ w tablicy II wykazały wpływ parametrów na wydajność procesu natryskiwania. Parametry wykorzystane dla grubości wejściowej 250 i $750 \mu \mathrm{m}$ różnią się praktycznie tylko prędkością podawania proszku, która dla cieńszej warstwy była 5 razy mniejsza. Okazuje się, że przyrost grubości jest jedynie ok. 3,5 razy większy. Wynika to $z$ mniejszej prędkości uzyskanej przez ziarna, które są w dużej ilości wprowadzone do strumienia. Kiedy porównamy dwie pierwsze założone grubości, tj. 250 i $500 \mu \mathrm{m}$, gdzie zwiększono 2 razy prędkość podawania proszku i zmniejszono również dwukrotnie prędkość liniową

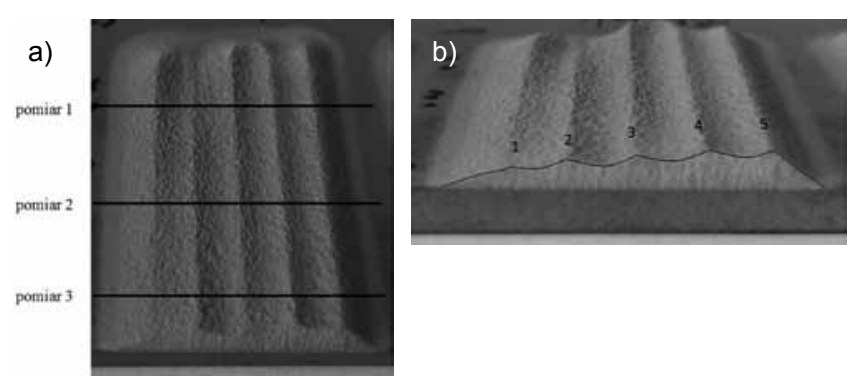

Rys. 3. Warstwa uzyskana w próbie 7 (tabl. II): a) miejsca pomiarów profilu warstwy, b) widok poprzeczny próbki

Fig. 3. Coatings deposited in experimental runs no. 7 (acc. to tab. II): a) location of surface profile measurements, b) trans-verse view of the sample 
a)

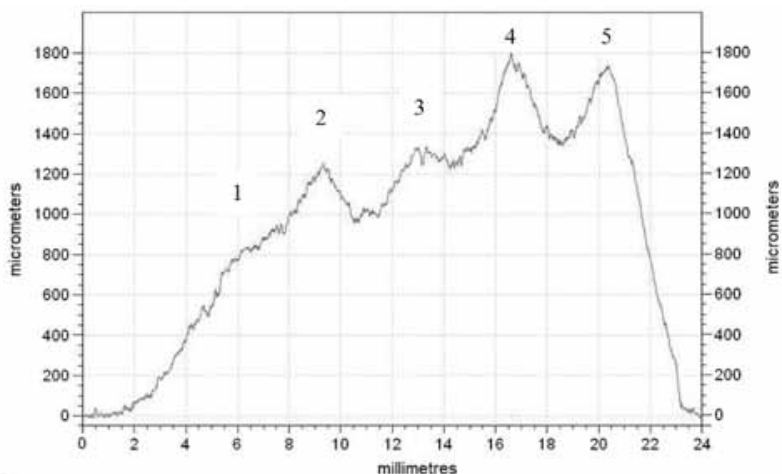

b)

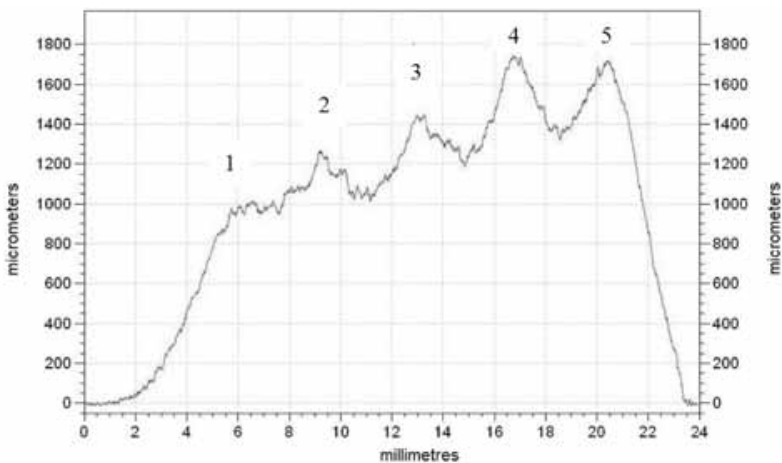

c)

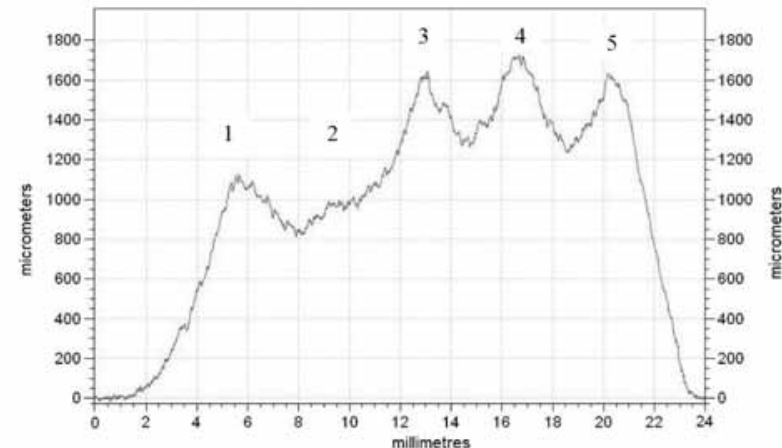

Rys. 4. Topografia warstwy z próby 7 (wg tabl. II): a) pomiar 3 , b) pomiar 2, c) pomiar 1

Fig. 4. Surface topography in 7 th probe (acc. to tab. II): a) measurement 3, b) measurement $2 \mathrm{c}$ ) measurement 1
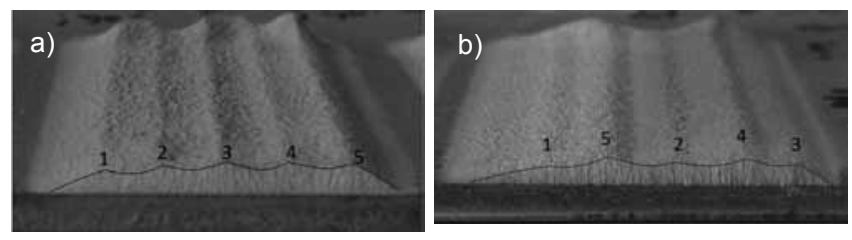

Rys. 5. Widok poprzeczny warstw o grubości $500 \mu \mathrm{m}$ (próba 3 i 4) naniesionych przy różnych odstępach a: 3,7 mm (a) oraz :7,4 mm (b) Fig. 5. Transverse view of coat-ings with thickness of $500 \mu \mathrm{m}$ created with different spray parame-ters: experimental run no. 3 (a) and experimental run no 4 (b)

palnika, grubość warstwy wzrosła niemalże trzykrotnie, co świadczy o zwiększeniu wydajności procesu.

Duży wpływ na profil warstwy miała również odległość między kolejnymi przejściami palnika a. Zjawisko nagrzewania się dyszy i palnika w 3 pierwszych przejściach prowadziło do ogromnej nierównomierności warstwy przy odległości a $=7,4 \mathrm{~mm}$, co przedstawiono na rysunku 5 . Stąd zaleca się stosowanie przejścia palnika w odległości $a=3,7 \mathrm{~mm}$.
Tabl. II. Uzyskane profile warstw o grubości $500 \mu \mathrm{m}$ (próba 3 i 4) naniesionych przy różnych odstępach a: $3,7 \mathrm{~mm}$ (a) oraz 7,4 mm (b) Table II. The $500 \mu \mathrm{m}$ thickness layer profiles (probe 3 and 4) made with different distances a: $3,7 \mathrm{~mm}$ (a) and 7,4 $\mathrm{mm}$ (b)

\begin{tabular}{|c|c|c|c|c|c|c|}
\hline $\begin{array}{l}\frac{\widehat{a}}{2} \\
\frac{0}{2} \\
\frac{2}{2}\end{array}$ & 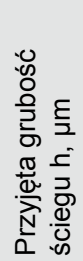 & 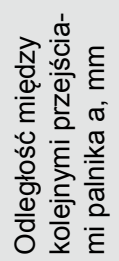 & 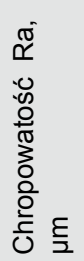 & 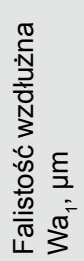 & 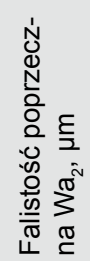 & 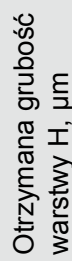 \\
\hline 1 & 250 & 3,7 & 8,5 & 24,2 & 46,7 & 494 \\
\hline 2 & 250 & 7,4 & 9,2 & 17,9 & 46,6 & 440 \\
\hline 3 & 500 & 3,7 & 12,2 & 18,8 & 55,6 & 1610 \\
\hline 4 & 500 & 7,4 & 12,3 & 16,9 & 121,8 & 1247 \\
\hline 5 & 750 & 3,7 & 10,4 & 20,4 & 95,6 & 1987 \\
\hline 6 & 750 & 7,4 & 10,1 & 79,0 & 144,7 & 1420 \\
\hline 7 & 1000 & 3,7 & 10,6 & 16,0 & 104,1 & 1738 \\
\hline 8 & 1000 & 7,4 & 10,8 & 17,2 & 145,6 & 1810 \\
\hline
\end{tabular}

Próby o grubości $\mathrm{h}=200 \mu \mathrm{m}$ i h $=750 \mu \mathrm{m}$ wykazały najmniejszą chropowatość Ra. Związane jest to z najwyższymi parametrami temperatury i ciśnienia, które w efekcie dają najwyższą prędkość ziaren proszku w strumieniu [9]. Dodatkowo zastosowano najwyższą prędkość liniową palnika, wynoszącą $1200 \mathrm{~mm} / \mathrm{min}$. Średnia chropowatość Ra w obu przypadkach wyniosła poniżej $10 \mu \mathrm{m}$. Zaobserwowano, że zwiększenie prędkości liniowej palnika prowadzi do zmniejszenia grubości warstwy, a wskutek tego do uzyskania mniej rozbudowanego podłoża. Przyrost grubości warstwy powoduje coraz bardziej rozbudowaną strukturę, stąd można przyjąć, że im większa grubość, tym wyższa chropowatość powierzchni. Najwyższą średnią chropowatość Ra uzyskano dla prób o założonej grubości $500 \mu \mathrm{m}$ - wynosiła ona 12,2 $\mu \mathrm{m}$. Wynika to $z$ niskiego ciśnienia procesu $0,5 \mathrm{MPa}$, które powodowało duże rozbieżności w prędkościach ziaren metalu i ceramiki, co dało w efekcie rozbudowane podłoże.

Falistość wzdłużna Wa ${ }_{1}$ osiągnęła najwyższe wartości przy próbach z największymi parametrami temperatury i ciśnienia gazu (próby nr 1, 2 i 5, 6), co związane jest bezpośrednio $z$ dużą prędkością ziaren w strumieniu. Największą wartość falistości wzdłużnej osiągnięto dla warstwy o grubości $750 \mu \mathrm{m}$, gdzie wykorzystano największą prędkość podawania proszku 1,73 g/s. Zarówno prędkość ziaren, jak i prędkość podawania proszku znacząco wpływają na falistość wzdłużną $\mathrm{Wa}_{1}$. Wynika to z podciśnieniowego podawania proszku, co powoduje wprowadzenie nieproporcjonalnej ilości proszku do strumienia oraz jego rozkład na podłożu. Przy małych ilościach proszku falistość wzdłużna jest niwelowana przez większą prędkość liniową.

Falistość poprzeczna $\mathrm{Wa}_{2}$ zależały przede wszystkim od odległości między kolejnymi przejściami palnika a. Najmniejsza falistość wystąiła przy warstwach o najmniejszej grubości, $250 \mu \mathrm{m}$. Należy więc przypuszczać, że występująca falistość wzdłużna dla każdego pojedynczego ściegu wpływa również na falistość poprzeczną całej warstwy. Największą falistością 
natomiast cechowały się warstwy wykonane przy próbach, dla których odległość między kolejnymi przejściami palnika a była równa $7,4 \mathrm{~mm}$. Okazuje się, że przy większych odległościach a na sąsiednich ściegach osadza się znacznie mniejsza ilość proszku, co powoduje powstanie warstwy o dużej falistości. Dla mniejszej odległości między kolejnymi przejściami palnika wynoszącej $\mathrm{a}=3,7 \mathrm{~mm}$ strumień obejmuje swoją powierzchnią czołową sąsiedni ścieg, co pozwala uzyskać równomiernie nałożoną warstwę.

\section{Wnioski}

Wyniki przeprowadzonych badań wykazały, że występuje znaczący, nawet dwukrotny, wzrost grubości warstwy w stosunku do grubości pojedynczych ściegów, ściśle powiązany z odległością międzyściegową. Wraz ze wzrostem odległości między kolejnymi przejściami palnika a można zaobserwować spadek grubości uzyskanych powłok, a także zwiększoną falistość poprzeczną, co spowodowane jest mniejszą ilością proszku osadzającego się na kolejnych ściegach.

Wzrost grubości spowodowany jest również nagrzewaniem się dyszy oraz podłoża w wyniku oddziaływania temperatury przepływającego gazu. Wraz z nagrzaniem dyszy zmieniają się warunki panujące $w$ jej wnętrzu, zmniejszają się straty ciepła i jednocześnie wzrasta prędkość ziaren proszku w strumieniu. Podgrzanie podłoża wywołuje wzrost wydajności procesu, co jest równoznaczne z osadzeniem większej ilości proszku i uzyskaniem grubszej warstwy.

Kluczowymi parametrami mającymi wpływ na chropowatość okazały się: temperatura, ciśnienie, wpływające na prędkość ziaren w strumieniu, oraz prędkość liniowa palnika. Wzrost tych parametrów powoduje spadek chropowatości. Zwiększenie prędkości liniowej palnika prowadzi do zmniejszenia grubości warstwy, a co za tym idzie - uzyskania mniej rozbudowanego podłoża.

Uzyskane wyniki wskazują na zależność falistości wzdłużnej od prędkości ziaren oraz prędkości podawania proszku. W związku z grawitacyjnym podawaniem proszku do strumienia trafia jego nieregularna ilość. Przy małych ilościach proszku falistość wzdłużna jest niwelowana przez większą prędkość liniową.

\section{Literatura}

[1] Katanoda H., Matsuoka T., Matsuo K.: Experimental Study on Shock Wave Structures in Constant-area Passage of Cold Spray Nozzle, Journal of Thermal Science, vol.16, no.1, 2006, s. 40-45.

[2] Jodoin B., Richer P., Bérubé G., Ajdelsztajn L., Erdi-Betchi A., Yandouzi M.: Pulsed-Gas Dynamic Spraying: Process analysis, development and selected coating examples, Surface \& Coatings Technology, vol. 201, 2007, s. 7544-7551.

[3] Xian-Jin Ning, Quan-Sheng Wang, Zhuang Ma, and HyungJun Kim: Numerical Study of In-flight Particle Parameters in Low-Pressure Cold Spray Process, Journal of Thermal Spray Technology vol. 19, no. 6, 2010, s. 1211-1217.

[4] Schmidt T., Gärtner F., Assadi H., Kreye H.: Development of a generalized parameter window for cold spray deposition, Acta Materialia, vol. 54, 2006, s. 729-742.

[5] Hussain T., McCartney D.G., Shipway P.H., Zhang D.: Bonding Mechanisms in Cold Spraying: The Contributions of Metallurgical and Mechanical Components, Journal of Thermal Spray Technology, vol. 18, no. 3, 2009, s. 364-379.

[6] Luzin V., Spencer K., Zhang M.-X.: Residual stress and thermo-mechanical properties of cold spray metal coatings, Acta Materialia, vol. 59, 2011, s. 1259-1270.

[7] Goyal R., Walia R. S., Sidhu T. S.: Study of Coating Thickness of Cold Spray Process Using Taguchi Method, Materials and Manufacturing Process, vol. 27, 2012, s. 185-192.

[8] Van Steenkiste T., Smith J.R.: Evaluation of coatings produced via kinetic and cold spray process, Journal of Thermal Spray Technology, vol. 13, no. 2, 2004, s. 274-282.

[9] Lima R. S., Kucuk A. C. C.: Berndt Deposition efficiency, mechanical properties and coating roughness in cold-sprayed titanium, Journal of Materials Science Letters, vol. 21, 2002 , 1687-1689.
[10] Balania K., Lahaa T., Agarwala A., Karthikeyanb J. N.: Munroea effect of carrier gases on microstructural and electrochemical behavior of cold-sprayed 1100 aluminum coating, Surface \& Coatings Technology, vol. 195, 2005, s. 272-279.

[11] Wang Q., Birbilis N., Zhang M.-X.: Interfacial structure between particles in an aluminum deposit produced by cold spray, Materials Letters, vol. 65, 2011, s. 1576-1578.

[12] Irissou E., Legoux J.-G., Arsenault B., Moreau Ch.: Investigation of $\mathrm{Al}-\mathrm{Al}_{2} \mathrm{O}_{3}$ Cold Spray Coating Formation and Properties, Journal of Thermal Spray Technology, vol. 16 (5-6), 2007, s. 661-668.

[13] Shkodkin A., Kashirin A., Klyuev O., Buzdygar T.: Metal Particle Deposition Stimulation by Surface Abrasive Treatment in Gas Dynamic Spraying, Journal of Thermal Spray Technology, vol. 15 (3), 2006, s. 382-386.

[14] Spencer K., Fabijanic D.M., Hang M.-X.: The use of $\mathrm{Al}-\mathrm{Al}_{2} \mathrm{O}_{3}$ cold spray coatings to improve the surface properties of magnesium alloys, Surface \& Coatings Technology, vol. 204, 2009, s. 336-344.

[15] Champagne V. K.: The cold spray materials deposition process: Fundamentals and applications, Woodhead Publishing Limited, Cambridge, 2007.

[16] Rech S., Trentin A., Vezzu S., Legoux J.-G., Irissou E. and Guagliano M.: Influence of Pre-Heated Al 6061 Substrate Temperature on the Residual Stresses of Multipass Al Coatings Deposited by Cold Spray, Journal of Thermal Spray Technology, vol. 20, no. 1-2, 2011, s. 243-251.

Artykuł powstał dzięki badaniom finansowanym przez Narodowe Centrum Nauki w ramach projektu nr 2011/01/N/ST8/04975, pt. „Adhesive properties of various material coatings deposition with low-pressure cold spraying". 